\title{
Production and Properties of Light Metal Matrix Nanocomposites
}

\author{
Hajo Dieringa $₫$ \\ Helmholtz-Zentrum Geesthacht, MagIC—Magnesium Innovation Centre, Max-Planck-Str. 1, \\ 21502 Geesthacht, Germany; hajo.dieringa@hzg.de
}

Received: 19 December 2019; Accepted: 2 January 2020; Published: 6 January 2020

\section{Background}

Metal matrix nanocomposites (MMNCs) with a light metal matrix are hybrid materials that have recently become the focus of interest for materials scientists and industry. While lightweight construction with conventional metal matrix composites (MMCs), which contain a high amount of reinforcing components ( $\mu \mathrm{m}$-particles, fibres, etc.), is counteracted by the fact that the density of the reinforcement is often significantly higher than that of the matrix, which is not disadvantageous with the low contents realized in nanocomposites. However, this advantage is at the expense of a difficulty caused by the very small size of the particles. The smaller they are, the larger their surface area, which increases the tendency of the nanoparticles to agglomerate (van der Waals forces) when stirred into a molten metal. In addition, the wettability is worse when the surface is large. This cluster formation can only be prevented with additional physical forces such as ultrasound, electromagnetic stirring, or mechanical shear forces [1].

When the particles have been distributed homogeneously in the melt, or are introduced into the matrix via other processes such as powder metallurgy or disintegrated melt deposition (DMD), the effect of the nanoparticles is remarkable. The size and the effect of the introduced ceramic particles is comparable to precipitates such as those produced in age-hardenable 6xxx or 7xxx aluminium alloys during heat treatment. However, while the precipitates coarsen when the ideal aging time is exceeded, thus again decreasing the high strength, the ceramic nanoparticles introduced are thermally stable as they have already survived in the molten metal if introduced via a melting metallurgical process.

The effects that the particles initiate in the light metal matrix are of different kinds. In some cases, it is Orowan strengthening, where the particles impede or stop the movement of dislocations. According to the following equation, the smaller the distance $\lambda$ between the particles, the greater this effect is, which increases the yield strength [2].

$$
\Delta \sigma_{O R}=\frac{0.13 b G_{m}}{\lambda} \ln \frac{d_{p}}{2 b} \text { with } \lambda=d_{p}\left[\left(\frac{1}{2 V_{p}}\right)^{1 / 3}-1\right]
$$

This can only be achieved with the same volume content of reinforcing phase by selecting very small particles [3]. In [2], the strengthening effect of $\mathrm{Al}_{2} \mathrm{O}_{3}$ nanoparticles in a magnesium matrix was simulated as a function of the particle size and it was shown that even with low contents of $20 \mathrm{~nm}$ particles, a strengthening effect could be achieved, which could not be obtained with $100 \mathrm{~nm}$ particles even in a much higher volume fraction.

Another effect is the grain refining effect of the nanoparticles. An increase in strength according to the Hall-Petch equation follows the equation below $[4,5]$.

$$
\sigma_{y}=\sigma_{0}+k_{y} D^{-1 / 2}
$$




\section{Contributions}

This special volume consists of one review and eight research papers. Of these nine papers, six deal with nanocomposites with a magnesium matrix and three with nanocomposites with an aluminium matrix. It becomes apparent that the property-enhancing effects of nanoparticles are more pronounced in magnesium than in aluminium.

The review paper by [6] describes the fabrication method using ultrasonic treatment and the mechanical properties of magnesium-based nanocomposites. The matrix used was pure magnesium as well as different alloys and a 1 or $2 \%$ addition of $\mathrm{SiC}, \mathrm{Al}_{2} \mathrm{O}_{3}, \mathrm{AlN}$, or carbon based materials served as nanoscale reinforcement. Significant increases in mechanical properties at the same time as ductility were achieved, and happened either by grain refinement or by Orowan strengthening.

In the first research paper of the Special Issue [7], the influences of laser-powder bed fusion on the microstructure as well as the mechanical and thermomechanical properties of an AlSi10Mg alloy with 0.5 wt.\% nano-spinel $\left(\mathrm{MgAl}_{2} \mathrm{O}_{4}\right)$ were studied. It was shown that the nanocomposites, which were characterized by a higher volumetric energy density (VED), showed a higher porosity and thus also worse mechanical properties. At the same volumetric energy density, the nanocomposites showed slightly better mechanical properties than the pure AlSi10Mg alloy. These influences must be taken into account when developing nanocomposites for laser powder bed fusion.

The influence of a calcium addition of 1 and $2 \%$ on the hot working behaviour of an $A Z 31-1.5 \mathrm{Al}_{2} \mathrm{O}_{3}$ nanocomposite was investigated in [8]. The materials were prepared using the disintegrated melt deposition process and processing maps were generated in a temperature range of $250-500{ }^{\circ} \mathrm{C}$ and at deformation rates of $0.0003-10 \mathrm{~s}^{-1}$. It was shown that calcium had a grain refining effect and an addition of $1 \%$ extended the range in which the material could be hot worked. This was defined as the optimum composition. An addition of $2 \%$ reduced or even prevented dynamic recrystallization. As in other previous publications, the tool of the Processing Maps could be used effectively to determine ideal temperatures and deformation rates for the respective material.

Pure aluminium and carbon nanotubes (MWCNT), graphene nanosheets, nano-alumina, and fine tungsten carbide were mixed in a powder metallurgical process [9]. Hardness measurements on the CNT composites showed the maximum with the addition of $0.5 \mathrm{wt} \%$ MWCNTs after mixing under ultrasound and subsequent sintering. In comparison with the other added components, the WC composite showed the highest hardness, followed by the graphene nanosheet composite.

Nanocomposites were manufactured once again using the DMD process and then extruded [10]. In this case, pure magnesium was mixed with different concentrations of nickel-titanium NiTi (Nitinol) nanoparticles. All materials were examined with regard to their microstructure, density, and mechanical properties. It was shown that the $\mathrm{Mg}_{2} \mathrm{Ni}$ and $\mathrm{NiTi}_{2}$ phases formed and the nanocomposite with $3 \%$ NiTi showed an increase in microhardness of $31 \%$ and an increase in compressive and tensile strength.

Pure aluminium was formed in the equal-channel angular pressing (ECAP) process and the mechanical properties and electrical conductivity were compared with nanocomposites of pure aluminium containing $\mathrm{Al}_{2} \mathrm{O}_{3}, \mathrm{TiB}_{2}$, and $\mathrm{TiC}$ particles [11]. While the alumina nanoparticles increased the hardness, no significant improvement in electrical conductivity could be achieved due to agglomerates of the nanoparticles. However, the mechanical properties could be significantly improved by adding $\mathrm{TiB}_{2}$ particles. Thus, the yield strength was increased from 38 to $103 \mathrm{MPa}$ and the tensile strength from 73 to $165 \mathrm{MPa}$.

Pure magnesium and an Mg-0.3Zn-0.3Y alloy were mixed with AlN nanoparticles using an ultrasound-assisted casting process and the castings were then extruded [12]. Both the as-cast and extruded materials were examined for texture, microstructure, and mechanical properties. In both materials, the strength in the cast state was increased by the addition of AlN nanoparticles. In pure magnesium, this also applied to the extruded state. In the ZW0303, there were special effects due to the $\mathrm{Al}$ impurities in the nanoparticles because the aluminium precipitated with yttrium, which in turn affected the grain size. This grain refinement had an influence on strength that was greater than the influence of the AlN nanoparticles. 
The hot working properties of an ML5 magnesium alloy that corresponded to AZ91 and was reinforced with $0.5 \mathrm{wt} . \%$ AlN nanoparticles were investigated in [13]. The mechanical properties of the nanocomposite were superior to those of the pure alloy in the quasi-static and shock wave tests. This was attributed to the grain refinement by the nanoparticles and to their strengthening effect in the grains. After heat treatment of the materials, an increase in the strength of the nanocomposites compared to the pure alloy was observed in some cases.

In another work by Manoj Gupta's group, pure magnesium was reinforced with superparamagnetic $\mathrm{Fe}_{2} \mathrm{O}_{3}$ nanoparticles to generate a material suitable for biomedical degradable implants [14]. The material was produced by the DMD process with subsequent extrusion and alternatively by a process where chips produced during turning are collected, compacted, and extruded. It was found that the $\mathrm{Fe}_{2} \mathrm{O}_{3}$ nanoparticles significantly improved the damping properties. In addition, the mechanical properties and degradation characteristics were significantly enhanced. This was most evident in the $\mathrm{Mg}-2 \mathrm{Fe}_{2} \mathrm{O}_{3}$ nanocomposite. The nanocomposites produced with the compacted chips showed a higher porosity and thus slightly worse properties, but the process is still interesting considering the mechanical properties and the possibility of recycling chips.

\section{Concluding Remarks}

Nanocomposites with an aluminium or magnesium matrix offer a wide range of properties. Both the physical and mechanical properties can be influenced by a suitable selection of the matrix alloy and the nanoparticles. It is already clear that excellent material properties can be achieved much more easily with a minor addition of nanoparticles than-as assumed twenty years ago-with 20 or 30\% $\mu$-scale particles.

In the future, not only these properties, but also additional functionalization will be possible with nanoscale particles. For example, one might not only think of doped particles, which enable the better visibility of degradable magnesium implants in magnetic resonance imaging (MRI), but also the influence of electrical or magnetic properties of light metals by appropriate nanoparticles seems possible. The topic "Metal Matrix Nanocomposites" will continue to grow and I hope that this Special Issue will make a valuable contribution.

Conflicts of Interest: The author declares no conflict of interest.

\section{References}

1. Sillekens, W.; Jarvis, D.J.; Vorozhtsov, A.; Bojarevics, V.; Badini, C.F.; Pavese, M.; Terzi, S.; Salvo, L.; Katsarou, L.; Dieringa, H. The ExoMet Project: EU/ESA Research on High-Performance Light-Metal Alloys and Nanocomposites. Metall. Mater. Trans. A 2014, 45A, 3349. [CrossRef]

2. Zhang, Z.; Chen, D.L. Consideration of Orowan strengthening effect in particulate-reinforced metal matrix nanocomposites: A model for predicting their yield strength. Scr. Mat. 2006, 54, 1321. [CrossRef]

3. Mirza, F.A.; Chen, D.L. A unified model for the prediction of yield strength in particulate-reinforced metal matrix nanocomposites. Materials 2015, 8, 5138-5153. [CrossRef] [PubMed]

4. Hall, E.O. The deformation and ageing of mild steel: III Discussion of Results. Phys. Soc. 1951, B64, 747. [CrossRef]

5. Petch, N.J. The Cleavage Strength of Polycrystals. J. Iron Steel Inst. 1953, 174, 25.

6. Dieringa, H. Processing of magnesium-based metal matrix nanocomposites by ultrasound-assisted particle dispersion: A review. Metals 2018, 8, 431. [CrossRef]

7. Marchese, G.; Aversa, A.; Lorusso, M.; Manfredi, D.; Calignano, F.; Lombardi, M.; Biamino, S.; Pavese, M. Development and characterisation of aluminium matrix nanocomposites AlSi10Mg/MgAl2O4 by laser powder bed fusion. Metals 2018, 8, 175. [CrossRef]

8. Rao, K.P.; Dharmendra, C.; Suresh, K.; Prasad, Y.V.R.K.; Gupta, M. Effect of calcium on the hot working behavior of AZ31-1.5 vol.\% nano-alumina composite prepared by disintegrated melt deposition (DMD) processing. Metals 2018, 8, 699. [CrossRef] 
9. Emadinia, O.; Vieira, M.T.; Vieira, M.F. Effect of reinforcement type and dispersion on the hardening of sintered pure aluminium. Metals 2018, 8, 786. [CrossRef]

10. Parande, G.; Manakari, V.; Wakeel, S.; Kujur, M.S.; Gupta, M. Enhancing mechanical response of monolithic magnesium using nano-NiTi (Nitinol) particles. Metals 2018, 8, 1014. [CrossRef]

11. Zhukov, I.A.; Kozulin, A.A.; Khrustalyov, A.P.; Matveev, A.E.; Platov, V.V.; Vorozhtsov, A.B.; Zhukova, T.V.; Promakhov, V.V. The impact of particle reinforcement with Al2O3, TiB2, and TiC and severe plastic deformation treatment on the combination of strength and electrical conductivity of pure aluminum. Metals 2019, 9, 65. [CrossRef]

12. Giannopoulou, D.; Dieringa, H.; Bohlen, J. Influence of AlN nanoparticle addition on microstructure and mechanical properties of extruded pure magnesium and an aluminum-free Mg-Zn-Y Alloy. Metals 2019, 9, 667. [CrossRef]

13. Khrustalyov, A.P.; Garkushin, G.V.; Zhukov, I.A.; Razorenov, S.V.; Vorozhtsov, A.B. Quasi-static and plate impact loading of cast magnesium alloy ML5 reinforced with aluminum nitride nanoparticles. Metals 2019, 9, 715. [CrossRef]

14. Johanes, M.; Tekumalla, S.; Gupta, M. Fe3O4 nanoparticle-reinforced magnesium nanocomposites processed via disintegrated melt deposition and turning-induced deformation techniques. Metals 2019, 9, 1225. [CrossRef]

(C) 2020 by the author. Licensee MDPI, Basel, Switzerland. This article is an open access article distributed under the terms and conditions of the Creative Commons Attribution (CC BY) license (http://creativecommons.org/licenses/by/4.0/). 